\title{
The Effect of Motor Performance on Sportive Performance of Children in Different Sports Branches
}

\author{
Zait Burak AKTUG ${ }^{1} \bowtie$ \\ Ruckan IRI ${ }^{2}$
}

${ }^{1.2}$ University of Nigde Omer Halisdemir, School of Physical Education and Sports, Nigde, Turkey

Email: zaithurak@omail.com.Tel: +90.5323355170

'Email: ruchaniri@ohu.edu.tr Tel: +905424378022

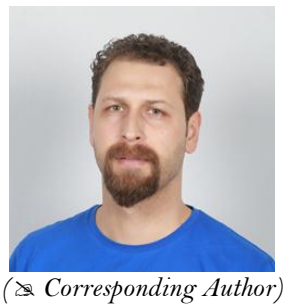

\begin{abstract}
The aim of the study is to investigate the relationship between motor performances of children aged 10-14 years and ball striking speeds made by specific technique and to determine motor performance differences between the branches. A total of 64 children (football $=22$, volleyball $=$ 19 , tennis $=23$ ) aged 10-14 years participated in the study. The motor performances of the children participating in the study were determined with the Dordel Koch Test and the ball hitting velocities with the radar instrument. The Spearman correlation analysis was used to determine the relationship between ball hitting velocities and motor performance, and the Kruskal-Wallis test was used to determine the difference between the engine performances of the branches. According to the results obtained, there was a positive correlation between the

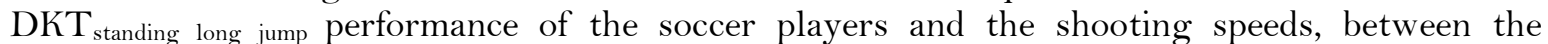
volleyball players' $\mathrm{DKT}_{\text {shuttle }}$ and $\mathrm{DKT}_{\text {push-up }}$ performances and the service speeds, between the $\mathrm{DKT}_{\text {shuttle }}$ and $\mathrm{DKT}_{\text {push-up }}$ performances of the tennis players and service and forehand strokes $\mathrm{p}<0.01$. It was determined that soccer players had higher performance than both tennis players

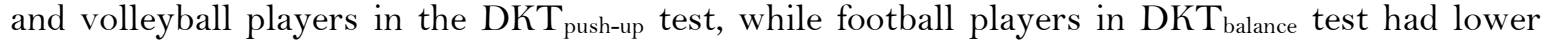
performance than both tennis players and volleyball players $\mathrm{p}<0.05$. As a result, it has been found that motor performances differ according to the children's branches. In addition, it is considered that the requirements of the sports branch (active use of the lower extremity, volleyball and upper extremity in the football) are effective on motor performance.
\end{abstract}

Keywords: Children, Dordel Koch test, Motor performance, Service speed, Shooting speed, Forehand-backhand speed.

Citation | Zait Burak AKTUG; Ruckan IRI (2018). The Effect of Motor Performance on Sportive Performance of Children in Different Sports Branches. Asian Journal of Education and Training, 4(2): 75-79.

History:

History:

February 2018

Revised: 16 February 2018

Accepted: 20 February 2018

Published: 23 February 2018

Licensed: This work is licensed under a Creative Commons

Attribution 3.0 License $(\mathrm{cc})$ (t)

Publisher:Asian Online Journal Publishing Group
Contribution/Acknowledgement: All authors contributed to the conception and design of the study.

Funding: This study received no specific financial support.

Competing Interests: The authors declare that they have no conflict of interests.

Transparency: The authors confirm that the manuscript is an honest, accurate, and transparent account of the study was reported; that no vital features of the study have been omitted; and that any discrepancies from the study as planned have been explained.

Ethical: This study follows all ethical practices during writing.

\section{Contents}

Introc

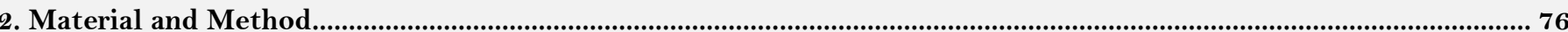

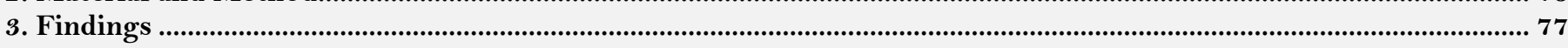

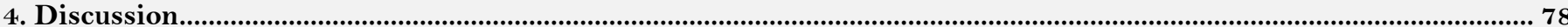

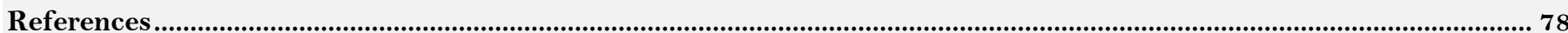




\section{Introduction}

Sports scientists have recently increased their efforts to determine motor skills and motor performance of children and adolescents (Iivonen et al., 2015). This is due to the fact that motor skills and motor performance are powerful indicators of children's health conditions and success in sports (Vandorpe et al., 2012a; Callewaert et al., 2015; Pion et al., 2015). It is evident that there are several factors that affect motor performance, one of which is the participation in sports.

Some studies have indicated that contribution of sports to motor skills is not high. For example, Vandorpe et al. $(2012 \mathrm{~b})$ found that children who actively participated in the activities of more than three years in athletic sports clubs work do not contribute to motor skills development in long-term. Contrary to the study conducted by Vandorpe et al. (2012b) there are studies showing that motor skills of those who actively participate in sport activities have improved. Rudd et al. (2014) reported that children aged 6-12 years whose motor skills are assessed through Test of Gross Motor Development-2 and Korpercoordination test für kinder (KTK), and suggested that 10-week gymnastic activities improved children's motor skills. In a similar study, Montezuma et al. (2011) reported that different dance activities improved children's motor skills.

Differences in the development of motor skills in children from the age of 10 onwards lead children to turn to any branch in sports. Leading children to different sports branches may result in differences in motor skills performances depending on the needs of the sport branch. When literature is examined, only 2 studies examining motor skills of children participating in different sports branches are available. Opstoel et al. (2015) identified motor skill differences in dance, ball games, gymnastics, racket games and swimming, and Timo et al. (2017) compared to the branches of swimmers, ice hockey and children performing gymnastics.

Motor skill is defined as a relatively stable general physical structure involving various aspects of motor ability (Vandorpe et al., 2012b; Lopes et al., 2013). Motor performance is defined as the action required to perform a motor task (Mosston and Ashworth, 1986) or as an action to perform a mobility skill (Gallahue et al., 2012) such as a 50 meter running speed, a ball throwing speed. There are studies in the literature evaluating motor performance and sportive performance. For example, Sögüt (2017) has found a positive relationship between motor skill and service speeds, examining the relationship between service speeds and the KTK motor skills test, in which motor performances such as balance, jumping and sideways movement of children playing tennis are determined.

The purpose of this study is to investigate the relationship between children's motor performances and specific speeds, and to determine motor performance differences between the branches. In addition, in the literature, KTK test, TGMD 2 test, Eurofit test and Bruininks-Oseretsky test were used in most of the studies on motor performance and motor performance, while Dordel Koch test was used to determine motor performance in the current study.

\section{Material and Method}

A total of 64 boys aged 10 to 14 years participated in the study. Twenty-two of the children participating in the study were 22 of them playing soccer, 19 of them were volleyball players and 23 of them were tennis players for 1 year. Measurements of children participating in the study were conducted through the Tanita BC-418 Segmental Body Analysis System (Tanita Corporation, Tokyo, Japan) using a standard steel stadiometer, lean feet with a precision of $0.1 \mathrm{~cm}$, bare weight measurement and no metal on. Children's BMIs are assessed by formula [body weight $(\mathrm{kg})$ / height $\left(\mathrm{m}^{2}\right)$ ]. With the Dordel Koch test, the shoot speeds of volleyball players, volleyball players' speeds, forehand, backhand, and service speeds of the tennis players were determined by radar tool with the help of push-ups, balance, standing-long jump, flexibility, sideward jump and 6 min running performance.

\subsection{Dordel Koch Test}

Dordel and Koch (2004) is a test designed to determine the motor performance and basic functions of children and young people aged 6-16 years. The Dordel-Koch Test consists of 7 different tests. 6 of which are grouped in the established stations (jumping, balancing, standing long jump, shuttle, push-up, flexibility), 6 min running was conducted as a final test. The best results were included in the study (Dordel and Koch, 2004).

$\mathrm{DKT}_{\text {sideward jump }}$ test; the child was folded four times in 15 seconds and applied at the highest speed on the fixed rope in the form of left and right jumping without touching the two feet and the ipe. The test was applied twice to the total score recorded.

$\mathrm{DKT}_{\text {flexibility }}$ test; is a test that measures the flexibility of the waist and especially the hamstring muscles. Children's feet are based on the base of the flexibility board, measured in a straight line extending to the last point where they can reach with their fingers. The point on which the foot base stands is determined as zero (O), the side on which the feet extend is positive $(+)$ and the side with the calf is negative $(-)$. The test was conducted twice and the best value was recorded in $\mathrm{cm}$.

$\mathrm{DKT}_{\text {standing-long jump }}$ test; the child was measured in the form of a double leg jumble to the farthest point where the legs can reach next, taking the force from the arms behind the determined zero. The last point of the child's heel was recorded in cm. 2 trials were implemented and the best result was included in the study.

$\mathrm{DKT}_{\text {shuttle }}$ test; the child's head is measured in the back of the head, with the jaws open sideways, and the body bent away from the knees and approaching the knees. Each full motion performed within 40 seconds was accepted as 1 and recorded as units.

$\mathrm{DKT}_{\text {balance }}$ test; children were measured as single legs for 60 seconds on a fixed rope in double layer. The number of contacts of the legs which was not on the rope was recorded as number.

$\mathrm{DKT}_{\text {push-up }}$ test; the children started the the push-up test while lying flat on, and the hands were on their hips. At the beginning of the allocated time, the hands were pressed under the shoulders and the body was lifted and the movement was completed by returning the starting position after touching one hand to another in the same position. The number of push-ups the child could make within 40 seconds was recorded as number.

$\mathrm{DKT}_{6 \text { min-running }}$ test; this test was conducted when the children ran around the area of a volleyball field $(54 \mathrm{~m})$ for 6 minutes as fast as possible. The children completed this length within 6 minutes either by running or walking when they felt tired. The total distance was recorded in metre. 
Each of the subscales of DKT are scored and evaluated separately, and a general score and evaluation are not conducted in DKT. DKT sub-dimension performances are indicated by scores from 1 to $6.1=$ very good, $2=$ good, $3=$ moderate, 4 = adequate, $5=$ poor, $6=$ very poor.

\subsection{The Determination of Velocity of Striking Ball}

Stalker Solo2 (Plano, USA) brand radar tool was used to measure the speed of the ball, which is specific to branches of soccer players, volleyball players and tennis players participating in the study. The soccer players' shooting speed of the ball was measured as they shot at $12 \mathrm{~m}$ away from the top at the highest speed (right and left). The volleyball players' speed was measured as they hit the ball with the service line running at the highest speed. The determination of the ball hit rates of tennis children was performed in the form of exhibits forehand, backhand and service strikes at the highest speed. All ball strikes were repeated twice and the best value was included in the study.

\subsection{Statistical Analysis}

After analyzing the data through the SPSS 24 packet program, the Kruskal-Wallis test was used to determine motor performance differences between the branches, and the Spearman Correlation Test was used to determine differences between motor performance and specific pulse rates. The level of significance in the study was accepted as $\mathrm{p}<0.01$ and $\mathrm{p}<0.05$.

\section{Findings}

Table-1. Average and prevalence of demographic variables of soccer, volleyball and tennis players

\begin{tabular}{l|l|l|l}
\hline & Soccer & Volleyball & Tennis \\
\hline $\mathbf{N}$ & 22 & 19 & 23 \\
\hline Age $($ year $)$ & $11.82 \pm 0.95$ & $13.05 \pm 0.85$ & $12.09 \pm 1.09$ \\
\hline Height $(\mathrm{m})$ & $1.54 \pm 0.13$ & $1.63 \pm 0.08$ & $1.55 \pm 0.09$ \\
\hline Kilo $(\mathrm{kg})$ & $44.75 \pm 17.55$ & $53.00 \pm 8.63$ & $43.26 \pm 8.42$ \\
\hline BMI $\left(\mathrm{kg} / \mathrm{m}^{2)}\right.$ & $19.42 \pm 5.43$ & $19.70 \pm 2.42$ & $17.79 \pm 2.50$ \\
\hline Sport Age (year) & $1.9 \pm 0.43$ & $2.44 \pm 0.56$ & $2.19 \pm 0.64$ \\
\hline
\end{tabular}

Table-2. Correlation between the radar velocities of soccer, volleyball and tennis players and the DKT subtests

\begin{tabular}{|c|c|c|c|c|c|c|c|c|c|}
\hline & $(\mathrm{km} / \mathrm{s})$ & & $\begin{array}{l}\text { DKT }_{\text {sideward }} \\
\text { jump }\end{array}$ & $D_{K T} T_{\text {flexibility }}$ & \begin{tabular}{|l|} 
DKT \\
jump
\end{tabular} & $\mathrm{DKT}_{\text {shutle }}$ & $\mathbf{D K T}_{\text {balance }}$ & DKT $_{\text {push-up }}$ & $\begin{array}{l}\text { DKT }_{6 \text { min }} \\
\text { running }\end{array}$ \\
\hline \multirow{6}{*}{ Soccer } & \multirow{3}{*}{$\begin{array}{l}\text { Shoot } \\
\text { (right) }\end{array}$} & $\mathrm{N}$ & 22 & 22 & 22 & 22 & 22 & 22 & 22 \\
\hline & & $\mathrm{p}$ & 0.14 & 0.76 & 0.00 & 0.21 & 0.25 & 0.31 & 0.81 \\
\hline & & $\mathrm{R}$ & 0.33 & -0.07 & 0.57 ** & 0.28 & -0.26 & 0.22 & 0.05 \\
\hline & \multirow{3}{*}{$\begin{array}{l}\text { Shoot } \\
\text { (left) }\end{array}$} & $\mathrm{N}$ & 22 & 22 & 22 & 22 & 22 & 22 & 22 \\
\hline & & $p$ & 0.26 & 0.15 & 0.01 & 0.19 & 0.18 & 0.32 & 0.92 \\
\hline & & $\mathrm{R}$ & 0.25 & -0.32 & 0.51 * & 0.29 & -0.30 & 0.22 & -0.02 \\
\hline \multirow{3}{*}{ Volleyball } & \multirow{3}{*}{ Service } & $\mathrm{N}$ & 19 & 19 & 19 & 19 & 19 & 19 & 19 \\
\hline & & $\mathrm{p}$ & 0.80 & 0.28 & 0.45 & 0.00 & 0.19 & 0.00 & 0.07 \\
\hline & & $\mathrm{R}$ & 0.06 & -0.26 & 0.18 & $0.64 * *$ & -0.31 & $0.72 * *$ & 0.43 \\
\hline \multirow{9}{*}{ Tennis } & \multirow{3}{*}{ Forehand } & $\mathrm{N}$ & 23 & 23 & 23 & 23 & 23 & 23 & 23 \\
\hline & & $\mathrm{p}$ & 0.53 & 0.51 & 0.06 & 0.00 & 0.09 & 0.03 & 0.79 \\
\hline & & $\mathrm{R}$ & -0.14 & 0.14 & 0.39 & $0.70^{* * *}$ & -0.35 & $0.43^{*}$ & 0.06 \\
\hline & \multirow{3}{*}{ Backhand } & $\mathrm{N}$ & 23 & 23 & 23 & 23 & 23 & 23 & 23 \\
\hline & & $\mathrm{p}$ & 0.41 & 0.55 & 0.23 & 0.15 & 0.95 & 0.18 & 0.48 \\
\hline & & $\mathrm{R}$ & -0.18 & 0.13 & 0.26 & 0.31 & -0.01 & 0.29 & 0.15 \\
\hline & \multirow{3}{*}{ Service } & $\mathrm{N}$ & 23 & 23 & 23 & 23 & 23 & 23 & 23 \\
\hline & & $\mathrm{p}$ & 0.79 & 0.66 & 0.22 & 0.18 & 0.90 & 0.53 & 0.22 \\
\hline & & $\mathrm{R}$ & -0.06 & -0.01 & 0.26 & 0.29 & 0.02 & 0.14 & 0.27 \\
\hline
\end{tabular}

$* * \mathrm{p}<0.01$

When Table 2 is examined, it is clear that soccer players have a positive relationship between right foot shooting speeds and standing long jump sub-test $(\mathrm{p}<0.01)$. It is also clear that there is a positive correlation between the left foot shooting speeds of the soccer players and the long jump subtest $(p<0.01)$. It is evident that there is a positive correlation between the service speeds of the volleyball players and the shuttle sub-test $(p<0.01)$. There is a significant positive correlation between service speeds of volleyball players and push-up sub-test ( $p$ $<0.01)$. There is a positive correlation between the forehand strike speeds of the tennis players and the shuttle subtest $(\mathrm{p}<0.01)$.

Table-3. Kruskal-Wallis test of soccer, volleyball, and tennis players comparing DKT subtests

\begin{tabular}{|c|c|c|c|c|c|c|c|c|c|c|}
\hline & \multicolumn{2}{|c|}{ 1. Soccer } & \multicolumn{2}{|c|}{ 2. Volleyball } & \multicolumn{2}{|c|}{ 3. Tennis } & \multirow{2}{*}{$\mathbf{X}$} & \multirow{2}{*}{ Sd } & \multirow{2}{*}{$\mathbf{p}$} & \multirow{2}{*}{$\begin{array}{l}\text { Post-hoc } \\
\text { Test }\end{array}$} \\
\hline & $\mathbf{N}$ & $\mathrm{x} \pm \mathrm{Sd}$ & $\mathbf{N}$ & $x \pm S d$ & $\mathbf{N}$ & $\mathbf{x} \pm \mathbf{S d}$ & & & & \\
\hline $\begin{array}{l}\text { DKT }_{\text {sideward }} \\
\text { jump }\end{array}$ & 22 & $34.50 \pm 7.02$ & 19 & $36.79 \pm 4.37$ & 23 & $32.65 \pm 4.88$ & 5.87 & 2 & 0.06 & \\
\hline $\mathrm{DKT}_{\text {flexibility }}$ & 22 & $-0.82 \pm 7.35$ & 19 & $4.68 \pm 8.38$ & 23 & $-5.17 \pm 6.14$ & 13.64 & 2 & $0.00^{*}$ & $2-1$ \\
\hline $\begin{array}{l}\text { DKT }_{\text {standing }} \\
\text { long jump }\end{array}$ & 22 & $146.64 \pm 21.62$ & 19 & $159.42 \pm 15.74$ & 23 & $137.00 \pm 20.97$ & 11.25 & 2 & $0.00 *$ & $2-1 / 2-3$ \\
\hline $\mathrm{DKT}_{\text {shutle }}$ & 22 & $21.32 \pm 7.23$ & 19 & $17.74 \pm 6.30$ & 23 & $15.83 \pm 6.86$ & 7.07 & 2 & $0.03 *$ & $1-3$ \\
\hline DKT $_{\text {balance }}$ & 22 & $1.50 \pm 1.41$ & 19 & $0.68 \pm 1.06$ & 23 & $0.78 \pm 1.31$ & 7.02 & 2 & $0.03 *$ & $1-2 / 1-3$ \\
\hline DKT $_{\text {push-up }}$ & 22 & $17.59 \pm 3.47$ & 19 & $14.11 \pm 4.03$ & 23 & $14.70 \pm 5.45$ & 8.23 & 2 & $0.01 *$ & $1-2 / 1-3$ \\
\hline $\begin{array}{l}\mathrm{DKT}_{6 \min } \\
\text { running }\end{array}$ & 22 & $\begin{array}{ll}883.36 & \pm \\
145.79 & \end{array}$ & 19 & $\begin{array}{ll}1007.95 & \pm \\
254.05 & \end{array}$ & 23 & $\begin{array}{ll}975.00 & \pm \\
202.67 & \end{array}$ & 4.04 & 2 & 0.13 & \\
\hline
\end{tabular}

${ }^{*} \mathrm{p}<0,05$ 
When Table 3 is examined, a significant difference is found between soccer and volleyball players in the flexibility subtest, and the difference is found to be in favor of volleyball players $(p<0.05)$. A significant difference is found between volleyball and tennis players in the flexibility test, and this difference is found to be in favor of volleyball players $(\mathrm{p}<0.05)$. A significant difference is found between the volleyball and tennis players in the standing long jump sub-test, and this difference is found to be in favor of volleyball players $(\mathrm{p}<0.05)$. A significant difference is found between soccer and tennis players in the shuttle test, and this difference is found to be in favor of soccer players $(\mathrm{p}<0.05)$. In the push-up subtest, a significant difference is found between soccer and volleyball players, and this difference is found to be in favor of soccer players $(p<0.05)$.

\section{Discussion}

In the current study, it is determined that Dordel Koch Test sub-dimension motor performance results are different depending on sports branches. There are only a few studies in the literature that have examined the motor skills of sports branches. In a study conducted on swimmers, ice hockey and gymnastic children by Timo et al. (2017) they found that gymnasts generally perform better than swimmers and ice hockey players. It was found that gymnasts had a higher balance performance than ice hockey players and swimmers.

It was found that in the right-left bounce test ice-hockey players had better performance than the swimmers and gymnastics, but the swimmers had better performance than the ice hockey players in the side-loading test. In another study conducted with children ages 9-11 by Opstoel et al. (2015) they classified children selected from 25 different sports branches as dancing, ball games, gymnastics, racket games and swimmers. Opstoel et al. (2015) stated that the severity of training was determined not by sports branches but by motor skills.

The results of this study is parallel with the results of Timo et al. (2017) and in their study, it was determined that motor performance varied depending on sports branches. This can be explained by the fact that the dominant requirements in the sport branch make it possible to develop different motor performances.

In the current study, it was examined the relationship between child's motor performances and specific ball

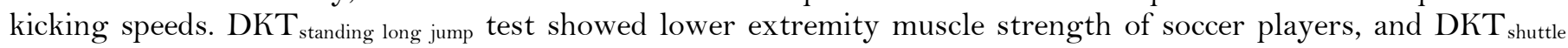
and $\mathrm{DKT}_{\text {push-up }}$ test showed upper extremity muscle strength of tennis and volleyball players. However, in the current literature, there are limited numbers of studies in the literature that examine motor skills and ball striking speeds.

Sögüt (2017) examined the relationship between motor skills and service speeds of tennis children who were classified as clubs and elites. Sögüt (2017) stated that elite athletes had higher motor skills and service speeds, which is related to the increase in motor skills due to the fact that elite tennis players performed more intensive training. In a similar study conducted by Farrell and Van De Braam (2015) they noted that the development of motor skills is important both in controlling body parts properly and successful strikes.

When the results of the study were examined, there was a positive relationship between the $\mathrm{DKT}_{\text {standing long jump }}$ performances of the soccer players and the shooting performances. This can be explained by the fact that quadriceps muscle strength is the main determinant of performance during both the shooting and long jump (Malliou et al., 2003). Similarly, there was a significant positive relationship between ball speeds and DKT $T_{\text {shutle }}$ and $\mathrm{DKT}_{\text {push-up }}$ test which determine upper extremity strength in the volleyball and tennis branches in which the upper extremity is heavily used. This can be explained by the fact that the body and arm muscles are a determining factor in the ball striking performance in both branches.

As a conclusion, it is determined that there are motor performance differences depending on the sports branches. It has also been determined that the sport branch has an effect on motor and sports performance.

\section{References}

Callewaert, M., J. Boone, B. Celie, D. De Clercq and J. Bourgois, 2015. Indicators of sailing performance in youth dinghy sailing. European Journal of Sport Sciences, 15(3): 213-2 19. View at Google Scholar $\mid$ View at Publisher

Dordel, S. and B. Koch, 2004. Basistest zur erfassung der motorischen leistungsfähigkeit von Kindern und Jugendlichen $[$ Test for the Assessment of Motor Performance of Children and Adolescent]. Cologne, Germany: Deutsche Sporthochschule Köln.

Farrell, P. and M. Van De Braam, 2015. Developing co-ordination for under 10 players. ITF Coaching and Sport Science Review, 65(23): 89.

Gallahue, L.D., J.C. Ozmun and D.J. Goodway, 2012. Understanding motor development, infants-children-adolescents-adults. 7 th Edn., The McGraw-Hill Companies. pp: 14.

Iivonen, S., A. Sääkslahti and A. Laukkanen, 2015. A review of studies using the Körperkoordinationstest für Kinder (KTK). European Journal of Adapted Physical Activity, 8(2): 18-36.

Lopes, L., R. Santos, B. Pereira and V. Lopes, 2013. Associations between gross motor coordination and academic achievement in elementary school children. Human Movement Science, 32(1): 9-20. View at Google Scholar | View at Publisher

Malliou, P., I. Ispirlidis, A. Beneka, K. Taxildaris and G. Godolis, 2003. Vertical jump and knee extensors isokinetic performance in professional soccer players related to the phase of the training period. Isokinetic and Exercises Sciences, 11(3): 165-169. View at Google Scholar

Montezuma, M., M. Rocha, R. Busto and D. Fujisawa, 2011. Hearing impaired adolescents: Dance learning and motor coordination. Special Education, 17(2): 321-334. View at Google Scholar

Mosston, M. and S. Ashworth, 1986. Teaching physical education. New York: Macmillan Collage Publishing Company. pp: 257.

Opstoel, K., J. Pion, M. Elferink-Gemser, E. Hartman, B. Willemse, R. Philippaerts, C. Visscher and M. Lenoir, 2015. Anthropometric characteristics, physical fitness and motor coordination of 9 to 11 year old children participating in a wide range of sports. PLoS One, 10(5): e0126282. View at Google Scholar | View at Publisher

Pion, J., J. Fransen, D. Deprez, V. Segers, R. Vaeyens, R.M. Philippaerts and M. Lenoir, 2015. Stature and jumping height are required in female volleyball, but motor coordination is a key factor for future elite success. Journal of Strength and Condination Research, 29(6): 1480-1485. View at Google Scholar | View at Publisher

Rudd, J., D. Farrow, L. Barnett, J. Berry, E. Borkoles and R. Polman, 2014. A pilot study to evaluate the efficacy of the 'la unchpad' gymnastics programme at developing children's motor coordination and fundamental movement skills. Journal of Science and Medicine Sport, 18(1): e1 1. View at Google Scholar | View at Publisher

Sögüt, M., 2017. A comparison of serve speed and motor coordination between elite and club level tennis players. Journal of Human Kinetics, 55(1): 171-176. View at Google Scholar | View at Publisher

Timo, J., A. Watt and S. Kalaja, 2017. Differences in the motor coordination abilities among adolescent gymnasts, swimmers, and ice hockey players. Human Movement Sciences, 18(1): 44-49. View at Google Scholar | View at Publisher 
Vandorpe, B., J. Vandendriessche, R. Vaeyens, J. Pion, S. Matthys, J. Lefevre, R.M. Philippaerts and M. Lenoir, 2012b. Relationship between sports participation and the level of motor coordination in childhood: A longitudinal approach. Journal of Science and Medicine Sport, 15(3): 220-225.

Vandorpe, B., J.B. Vandendriessche, R. Vaeyens, J. Pion, J. Lefevre, R.M. Philippaerts and M. Lenoir, 2012a. The value of a non-sport-specific motor test battery in predicting performance in young female gymnasts. Journal of Sport Sciences, 30(5): 497-505. 